\title{
Comparison of nest defence behaviour between two associate passerines
}

\author{
Marcin Polak
}

Received: 20 February 2012/ Accepted: 20 July 2012/Published online: 23 August 2012

(C) The Author(s) 2012. This article is published with open access at Springerlink.com

\begin{abstract}
Nest predation is one of the most important factors limiting reproductive success, and antipredator behaviour can significantly reduce the loss of avian broods. I carried out field experiments on two sympatric passerines: the barred warbler and the red-backed shrike. Many authors have described the protective nature of nesting association between these species. However, we have little knowledge about the true nature of the relationships between associates. I examined (1) whether barred warblers and redbacked shrikes respond differently to an avian predator, and (2) whether males and females differ in the intensity of nest defence. Decoys of a known nest predator and a nonpredatory control species were used to examine the types and relative intensity of parental response. I measured behavioural responsiveness by recording aggressive behaviour toward each model during the nestling period. Barred warblers and red-backed shrikes showed considerable variation in their response. Warblers more vigorously defended their own territories than shrikes. No differences between the sexes in antipredator behaviour in red-backed shrike were found. By contrast, in barred warbler, male was more involved in nest defence. The experimental tests provide evidence that these two species are able to differentiate between a predator and non-predator species.
\end{abstract}

Keywords Positive interactions - Protective nesting association $\cdot$ Nest defence $\cdot$ Antipredatory response

\footnotetext{
M. Polak $(\bowtie)$

Department of Nature Conservation, Institute of Biology and Biochemistry, Maria Curie-Skłodowska University, Akademicka 19, 20-033 Lublin, Poland

e-mail: mpolak@hektor.umcs.lublin.pl
}

\section{Introduction}

Recent empirical studies have suggested that positive interactions may be common, predictable and pervasive important forces in different ecosystems (Blanco and Tella 1997; Martin and Martin 2001; Quinn et al. 2003; Sergio et al. 2004; van Kleef et al. 2007; Nocera et al. 2009). Protection of broods from predators using aggressive behaviour of other species is one of the most unusual strategies used by birds to evade predation (Clark and Robertson 1979; Norrdahl et al. 1995). One such strategy is the creation of protective nesting associations in which one or more species relate and directly benefit from nesting within the protective umbrella created by other species (Blomqvist and Elander 1988; Halme et al. 2004). In the majority of cases, the protective nesting association occurs between a less aggressive species and a more aggressive species (often a raptor; Post and Seals 1993; Blanco and Tella 1997; but see Sergio et al. 2004). Moreover, in birds reproductive success may increase with the number of close, aggressive neighbours, including heterospecifics and conspecifics, because recent studies suggest a direct relationship between group size and mobbing intensity (Pavel and Bureš 2001; Grim 2008; Krama et al. 2012). Profit for individuals nesting in close proximity to an aggressive neighbour is mainly better protection against predators resulting in increased breeding success (Richardson and Bolen 1999). Animals may also refer other additional benefits such as more effective escape from an approaching predator through an early warning system, lower parasitism, the dilution effect against nest predation provided by other nests in the surroundings, higher mating success and therefore better breeding success (Clark and Robertson 1979; Bogliani et al. 1999; Quinn and Ueta 2008). Moreover, recent studies have indeed revealed that conspecifics 
and heterospecifics are used as a source of information concerning habitat quality, predation risk and food location (Forsman et al. 2008). There are costs associated with mobbing predators, including direct mortality or injury caused by a predator (Montgomerie and Weatherhead 1988), and reduction in the time and energy available for other essential activities. Protected associates sometimes also pay costs when their aggressive associate kills them or their young, or when they are forced to abandon their territory (Ebbinge and Spaans 2002). Although descriptive studies on protective nesting associations are fairly extensive (Blomqvist and Elander 1988; Post and Seals 1993; van Kleef et al. 2007), experimental tests are urgently needed to determine the fitness costs and benefits to species involved in positive behavioural interactions (Haemig 2001; Quinn and Ueta 2008).

Risk of predation has played a central role in the evolution of avian life strategies (Conway and Martin 2000). Animals, trying to minimise the risk of predation, use a variety of behavioural adaptations (Regelmann and Curio 1983; Quinn and Ueta 2008). Nest predation is one of the most important factors limiting reproductive success, and antipredator behaviour can significantly reduce the loss of avian broods (Grim 2008). The main factors affecting the nest defence intensity are: sex of parents (Požgayová et al. 2009), potential for renesting (Hogstad 2005), value of nestlings (Pavel and Bureš 2001), age and parental experience (Stenhouse et al. 2005), the group effect in mobbing (Pavel and Bureš 2001; Grim 2008), predator distance and type (Klvaňová et al. 2011) and nest construction and concealment (Kryštofková et al. 2011). However, the ways in which birds assess the risk of nest predation in unclear, and we have poor knowledge regarding how nest defence interacts with other aspects of decision-making by parents (Lima 2009), especially in the context of the creation of protective nesting associations. According to predictions of the dynamic risk assessment hypothesis (Kleindorfer et al. 2005), for mobbing birds, it is essential to assess the imminent risk and adjust their investment in antipredator behaviour.

Investigations of parental investment strategies are typically conducted on a single species, whereas comparisons between species are rare (Ghalambor and Martin 2000). Here I experimentally test for differences in antipredator behaviour between two sympatric passerines: the barred warbler Sylvia nisoria and the red-backed shrike Lanius collurio. Many researchers have described the association between these two avian species (Nankinov and Darakchiev 1979; Neuschulz 1981, 1988), but some authors suggest that this is an apparent relationship resulting from similar habitat preference (Gotzman 1965; Kuźniak et al. 2001). It is possible that one or two associate species benefit directly from protection afforded by the other associate because the latter forms a protective umbrella around its own nest. Barred warbler as the biggest sylviid warbler in central Europe is not afraid to nest in the neighbourhood of red-backed shrike. In addition, both species share the same predators (Neuschulz 1988; Goławski 2007). In this study, I compare barred warbler and red-backed shrike nest defence behaviour towards a stuffed model of the hooded crow Corvus cornix and as a control-a stuffed model of the green woodpecker Picus viridis. Red-backed shrikes are heavier than barred warblers (25-36.5 versus $21.5-32.0 \mathrm{~g}$, respectively; Cramp 1992; Kuźniak and Tryjanowski 2003; Tøttrup et al. 2011) and dominate in aggressive interactions between the two species (Polak M., unpublished data). Moreover, shrikes are raptorial passerines and have a thick, hooked beak and strong legs (Cramp 1992). In this context red-backed shrike should be the protective associate, and barred warbler as a protected associate would show less aggressive response toward a predator and would "parasitize" for the shrike's mobbing reaction. In contrary to this, recent study indicated that red-backed shrike had higher breeding success while breeding close to barred warbler territories (Goławski 2007). It was supposed that close nesting of these two species reduces the risk of predation due to barred warblers that actively attack predators (Cramp 1992). Moreover, according to recent research (Stenhouse et al. 2005; Grim 2008; Welbergen and Davies 2011), I also expected that shrikes and warblers would be able to discriminate between predators and harmless animals and that nest defence intensity should be higher in males than females (Pavel and Bureš 2001; Klvaňová et al. 2011; Kryštofková et al. 2011). This research focusses on the following detailed questions: (1) Which of these two species exhibits more intense antipredator behaviour? (2) Whether the distance between the focal nest and associate (both conspecific and heterospecific) could affect the decision of the birds to join mobbing of a predator at a neighbouring nest. (3) Whether they are able to distinguish between predators and a nonpredatory species. (4) Are there differences between sexes in their defensive effort? (5) Whether some features of offspring (brood size, brood age and laying date) may affect the intensity of nest defence behaviour.

\section{Materials and methods}

The field experiment examined whether the type of decoy affected the behavioural response of warblers and shrikes, by comparing their reaction to a known predator and a nonpredatory species. The study was carried out in a research area located in Lublin Region near Stężyca at middle Vistula River valley (central Poland, N 51 $1^{\circ} 34^{\prime}$; E $21^{\circ} 48^{\prime}$ ). The study plot is located in a partly used, strongly lit pasture, which because of limited grazing, in the last few 
years has undergone intense vegetation succession. A dry meadow with hawthorn Crataegus sp. thickets dominates the landscape. Since 2009, I have studied and monitored the populations of barred warblers and red-backed shrikes breeding in this area. The density of shrikes varied from 3.4 to 4.5 pairs (territories)/10 ha, and of warblers varied between 2.2 and 3.2 pairs (territories)/10 ha (Polak 2012). All active nests were visited at least once a week from May to July to collect data on breeding parameters. To reduce the impact of nest visits on predation risk, the number of controls was reduced to a minimum, especially in the incubation stage. Laying and hatching dates were directly observed or derived from chick measurements (Kuźniak and Tryjanowski 2003; Polak M., unpublished data). The behavioural tests were conducted in June and July of 2010 and 2011. To measure aggression against a nest predator, I presented a stuffed hooded crow. Hooded crow is one of the most important predators of broods of the studied species on the study plot, and its presence strongly affects the behaviour and breeding success of these birds (Polak M., unpublished data). To test predator discrimination, a stuffed model of a green woodpecker was included. Both breeding hooded crows and green woodpeckers were present at the study plot. All but three tested barred warblers were not colour-ringed; I cannot rule out a possibility of testing the same individuals repeatedly in the second breeding season, but I consider it as unlikely since I worked each season in different parts of the study plot. Moreover, it was found that barred warbler and red-backed shrike populations in Central Europe have low breeding philopatry (Neuschulz 1988; Tryjanowski et al. 2007). The decoys were placed in a natural perching posture, without using any luring mechanism (such as playback or movement). All tests were performed in an area with low vegetation height so that they were easily detectable by birds. The presentation of the two different model species was randomized. The location of models in relation to nests was the same in the two treatments. I presented the two models (predator and control) to parents of 16 red-backed shrike and 13 barred warbler nests. All experiments took place within the nestling period. The trials were undertaken at different times of the day from morning to evening in calm and dry weather.

Before conducting the experiments, I measured nearby trunks and branches, which allowed me to accurately determine the bird's approach distances. The models were mounted on a stick at the same height of $1.2 \mathrm{~m}$ above the ground. They were placed at the same distance of $5 \mathrm{~m}$ from the two species' nests, because nest defence is well known to decrease in intensity with distance from the brood (Kryštofková et al. 2011). The decoys were installed when no bird was nearby to minimise any potential disturbance effects. During each session, the behaviour of birds was noted by a single researcher. I observed and evaluated the behaviour of the adult shrikes and warblers from a hiding place. Both parents were recorded at the same time. Each trial consisted of $30 \mathrm{~min}$ of continuous focal sampling of behaviour. During the experimental tests I paid special attention and monitored neighbours who may have assisted the nest owners. Generally, the nest defence behaviour of each bird was measured using three different variables: aggression score, length of alarm reaction and minimum distance to the model. The aggression score was categorized separately for males and females on a scale from 0 to 7 . The rank values of mobbing behaviour were assigned according to its increasing degree of risk: 0 , no response to the model; 1 , bird mobs from a distance of at least $10 \mathrm{~m}$ without alarm calls; 2, calling bird from a distance of at least $10 \mathrm{~m} ; 3$, no alarm calls, bird mobs from a distance of up to $10 \mathrm{~m} ; 4$, calling bird close to the model $(<10 \mathrm{~m})$, but does not fly in the direction of the model; 5 , bird mobs intensively and flies to the model, but does not attack; 6 , bird attacks decoy, but without contact; 7, bird attacks model with contact. For further analyses the most extreme aggressive response from all reactions performed by each individual during $30 \mathrm{~min}$ of a trial was considered. The definition of alarm reaction included repetitive alarm calling, bill clattering, tail mowing and characteristic display behaviours (Cramp 1992, 1993). Additionally, for birds responding aggressively to the models, the parental latency period (the amount of time elapsed from the time the nest was exposed to the model until the time of first mobbing reaction by a male and/or female) was measured. The exact coordinates and distances between conspecific and heterospecific nests were measured by global positioning system (GPS) receiver.

I used STATISTICA 6.0 for Windows software (2001) for data analysis. I compared the responses elicited during the double treatments of predator and non-predator models at warbler and shrike nests by using repeated-measures analysis of variance (ANOVA), with the type of presentation and sex of parents as the independent factors and aggression score, length of alarm reaction and minimum distance to the model as dependent variables. The parental latency period between shrikes and warblers was analysed by using the $t$ test with Bonferroni correction. To find out whether the aggression score (both sexes pooled) and joining to communal defence behaviour (as a binary variable) were influenced by different parameters, I conducted analyses of covariance (ANCOVAs) with year as the categorical factor and laying date, brood size, nestling age (the age of the oldest nestling in days), conspecific distance and heterospecific distance as continuous predictors. To avoid the effect of year on the laying date, the data were standardised by the formula: $1=$ the first egg date in the population in each year. The frequencies of neighbour's responses during experiments were analysed by using Fisher's exact test. Means are expressed \pm standard deviation (SD), and all tests are two-tailed. 
Table 1 Mean $( \pm \mathrm{SD})$ aggression score, reaction time and closest distance of male and female barred warblers and red-backed shrikes in response to the different decoy types

\begin{tabular}{|c|c|c|c|c|c|}
\hline \multirow[t]{2}{*}{ Variable } & \multirow[t]{2}{*}{ Type of decoy } & \multicolumn{2}{|c|}{ Barred warbler } & \multicolumn{2}{|c|}{ Red-backed shrike } \\
\hline & & Male & Female & Male & Female \\
\hline \multirow[t]{2}{*}{ Aggression score } & Predator & $3.8 \pm 1.2$ & $3.5 \pm 1.6$ & $2.1 \pm 2.2$ & $1.1 \pm 2.0$ \\
\hline & Control & $1.3 \pm 1.3$ & $0.5 \pm 1.2$ & $1.4 \pm 1.4$ & $1.3 \pm 1.8$ \\
\hline \multirow[t]{2}{*}{ Reaction time (min) } & Predator & $21.3 \pm 8.7$ & $9.1 \pm 8.3$ & $6.7 \pm 8.9$ & $6.5 \pm 7.4$ \\
\hline & Control & $1.5 \pm 1.8$ & $0.2 \pm 0.6$ & $1.5 \pm 3.3$ & $1.4 \pm 2.1$ \\
\hline \multirow[t]{2}{*}{ Distance (m) } & Predator & $4.9 \pm 2.4$ & $6.0 \pm 2.1$ & $17.4 \pm 16.4$ & $18.4 \pm 20.7$ \\
\hline & Control & $14.8 \pm 10.6$ & $9.6 \pm 10.4$ & $8.3 \pm 7.5$ & $8.0 \pm 7.7$ \\
\hline
\end{tabular}

\section{Results}

Both species were more aggressive toward the predator than toward the control model (repeated-measures ANOVA, $F_{2,112}=27.56, \quad P<0.0001$, Table 1). The aggression response level was also significantly influenced by the species $\left(F_{2,112}=6.58, P=0.012\right)$, with barred warblers being more aggressive than red-backed shrikes. Interaction between both factors was also significant (model $\times$ species, $\left.F_{2,112}=12.53, P<0.001\right)$. There were no sex-related differences in aggression score for barred warblers $\left(F_{1,50}=\right.$ $1.21, P=0.277)$ or red-backed shrikes $\left(F_{1,62}=0.21\right.$, $P=0.649)$. The length of reaction time was significantly influenced by the species, where warblers reacted longer than shrikes $\left(F_{2,112}=10.34, P<0.005\right.$, Table 1$)$, and by the model $\left(F_{2,112}=60.52, P<0.00001\right)$. Both species had stronger response toward predator than the non-predator model. Interaction between both factors was also significant (model $\times$ species, $\left.F_{2,112}=13.40, P<0.0005\right)$. Male barred warblers reacted much longer than females $\left(F_{1,50}=\right.$ $6.15, P=0.017)$. However, there were no sex-related differences in reaction time for red-backed shrikes $\left(F_{1,62}=\right.$ $0.01, P=0.924)$. Warblers and shrikes approached the predator model to similar distance (Table $1, F_{2,112}=3.72$, $P=0.056)$, however the model $\times$ species interaction was significant $\left(F_{2,112}=14.40, P<0.005\right)$, but the type of model did not significantly influence the distance between birds and the decoy $\left(F_{2,112}=0.49, P=0.485\right)$. There were no sex-related differences in approach distance to the models in warblers $\left(F_{1,50}=0.78, P=0.381\right)$ or shrikes $\left(F_{1,62}=0.01, \quad P=0.928\right)$. Barred warblers (mean $=$ $2.4 \pm 2.0 \mathrm{~min}, n=12)$ reacted more quickly than redbacked shrikes (mean $=4.4 \pm 3.5 \min , n=14$ ) to the predator model, but there were no significant species differences in the latency period $(t$ test, $t=-1.71, d f=24$, $P=0.10)$. When using a non-predator model, there was no such difference $(t=-0,18, d f=15, P=0.86)$ between warblers (mean $=5.5 \pm 6.3 \mathrm{~min}, n=8$ ) and shrikes (mean $=6.1 \pm 6.9 \min , n=9$ ). Year, brood size, brood
Table 2 Number of mobs attended by neighbouring barred warblers and red-backed shrikes during sessions with crow model

\begin{tabular}{lll}
\hline Experimental trials/species & $\begin{array}{l}\text { Barred } \\
\text { warbler }\end{array}$ & $\begin{array}{l}\text { Red-backed } \\
\text { shrike }\end{array}$ \\
\hline At barred warbler nest $(n=13)$ & $7(54 \%)$ & $1(8 \%)$ \\
At red-backed shrike nest $(n=16)$ & $3(19 \%)$ & $1(6 \%)$ \\
\hline
\end{tabular}

age, conspecific distance, heterospecific distance and standardised laying date did not significantly contribute to parental aggression score in red-backed shrike (ANCOVA, all $F_{1,14} \leq 2.33$, all $P \geq 0.16$ ) or in barred warbler (ANCOVA, all $F_{1,11} \leq 1.91$, all $P \geq 0.22$ ).

The individuals in some experimental sessions joined together to mob the model predator by cooperatively attacking it. Communal defence in both conspecific and heterospecific associate was most frequently observed in barred warbler than red-backed shrike. In one case, the size of the mobbing group was three warbler pairs nesting next to each other. Table 2 presents the frequencies of neighbour's responses during experiments. Barred warblers were more likely to attack crow at warbler nests than shrike broods (Fisher's exact test, $P<0.05$ ), while in red-backed shrike there were no differences (Fisher's exact test, $P=0.60)$. Mean \pm SD distances between neighbouring nests were as follows: L. collurio- $L$. collurio -73.8 $\pm 33.6 \mathrm{~m}$ (23-129 $\mathrm{m}, \quad n=16)$, L. collurio-S. nisoria$117.4 \pm 89.6 \mathrm{~m}(13-310 \mathrm{~m}, n=16), S$. nisoria-S. nisoria$137.2 \pm 86.3 \mathrm{~m}(51-320 \mathrm{~m}, n=13)$. Year, brood size, brood age, conspecific distance, heterospecific distance and standardised laying date did not significantly contribute to heterospecific communal defence in warblers (ANCOVA, all $F_{1,11} \leq 0.63$, all $P \geq 0.46$ ). However, two variables were identified as influencing the conspecific communal defence in barred warbler: standardised laying date (ANCOVA, $F_{1,11}=6.35, P<0.05$ ) and conspecific distance (ANCOVA, $F_{1,11}=5.80, P=0.05$ ). Birds form early broods and breeding close to each other were more involved in cooperation against predator. In red-backed 
shrike no factors had a significant impact on conspecific and heterospecific communal defence (ANCOVA, all $F_{1,14} \leq 1.79$, all $P \geq 0.21$ ).

\section{Discussion}

These two sympatric passerine birds significantly differed in their overall responses to the predator. Barred warblers defended their own territories more vigorously than redbacked shrike. Warblers reacted intensely, and the length of reaction time was significantly longer. These birds more quickly detected a threat and approached more closely to a predator model than shrikes. Moreover, barred warblers more frequently participated in communal defence involving neighbouring nesters. According to the predictions of the "calling for help" hypothesis (Pavel and Bureš 2001; Grim 2008; Krama et al. 2012), a higher defensive effort by barred warblers attracted more neighbouring birds to the defended nest. The communal nest defence in this species was also described in earlier studies (Neuschulz 1981, 1988). The results of this study are in accordance with recent research. Goławski (2007) found that the breeding success of red-backed shrikes nesting in the vicinity of warbler territories is higher than shrikes nesting alone. The author supposed that this may be due to the aggression of barred warblers towards potential predators.

Different life strategies may cause differential defensive efforts between these species (Blanco and Tella 1997; Ghalambor and Martin 2000). Avian species that live a long time maximise their life reproductive success and are therefore not willing to take a high risk in defence of the brood in a particular breeding season, because the loss of a brood can be compensated for in future years (Pavel and Bureš 2001; Ebbinge and Spaans 2002; Mönkkönen et al. 2007). However, the available data suggest that warblers and shrikes have similar lifespans (http://www.euring.org), and this factor is unlikely to have a significant impact on the observed pattern. The more possible explanation of asymmetry in antipredatory behaviours between warblers and shrikes may be due to interspecific differences in the possibility to repeat a lost brood during one breeding period (Halupka and Halupka 1997; Hogstad 2005; Klvaňová et al. 2011). Both species are long-distance and intercontinental migrants who spend only a small part of their annual life cycle at the breeding areas (Cramp 1992, 1993; Tøttrup et al. 2011). At the beginning of the autumn migration, warblers leave the nest sites more quickly than shrikes (Dyrcz et al. 1991; Tomiałojć and Stawarczyk 2003). Therefore, the reproductive window of barred warblers is extremely short, and it is likely that their renesting potential is lower throughout the season and that their current breeding attempt is of maximum value from the start. In the study population, from all broods of warblers only $3 \%$ of all broods were repeated, but in the case of shrikes the proportion was much higher and amounted to $15 \%$ (Polak M., unpublished data). Moreover, in the studied population red-backed shrikes had significantly higher reproductive success in repeated broods than in the primary broods. Lack of or limited opportunities to repeat clutches in warblers could cause increased parental investment in their current brood (Halupka and Halupka 1997; Pavel and Bureš 2001; Hollander et al. 2008).

According to predictions of the dynamic risk assessment hypothesis (Kleindorfer et al. 2005), for mobbing birds, it is essential to assess the imminent risk and distinguish between predators and harmless animals. These findings provide evidence that these birds were able to distinguish between a predator and non-predatory species. There is growing evidence that various bird species are able to discriminate between predators and harmless animals (Hogstad 2005; Stenhouse et al. 2005; Grim 2008; Welbergen and Davies 2011). Discrimination among different types of intruders seems to be advantageous for individuals, because this enables unnecessary aggressive interactions to be reduced in order to minimise the energy costs of defence during the breeding period (Hogstad 2004; Kryštofková et al. 2011).

Barred warblers and red-backed shrikes showed considerable variation in their response. Some breeding pairs were very aggressive and quickly reacted to the predator model, while others demonstrated neutrality towards a decoy. Here, the presented experimental tests showed that differences in mobbing behaviour between the birds were not dependent on the number and age of offspring. Recent studies indicate that age and personality of birds are the most important factors influencing the involvement and intensity of brood defence against predators (Halupka and Halupka 1997; Stenhouse et al. 2005; Hollander et al. 2008; Kryštofková et al. 2011). Unfortunately, in these studies the experience and personality of individuals were not investigated further.

The contributions to defensive effort are likely to be unequally divided between males and females because of differences in their size, condition and parental investment (Požgayová et al. 2009). Here, the presented experimental tests indicate no differences between the sexes in defensive behaviour in red-backed shrike. Similarly, Tryjanowski and Goławski (2004) also found no gender differences in antipredatory response in this species. By contrast, barred warbler male was more involved in nest defence. Male warblers reacted particularly much longer than females. Possibly, male level of aggression during the nestling phase may be higher in barred warbler than in red-backed shrike due to the heterospecific differences in allocation of parental investment (Cramp 1992, 1993). Moreover, barred 
warbler males have well-spaced barring on underparts, and recently new evidence has been collected that underpart barring in bird plumage may have warning functions and can help in effective deterrence of intruders (Welbergen and Davies 2011). Most authors demonstrated higher intensity of mobbing in nest defence in males than in females in various bird species (Regelmann and Curio 1986; Pavel and Bureš 2001; Klvaňová et al. 2011; Kryštofková et al. 2011). First, antipredatory response may be a part of self-advertisement and evidence of male quality (Hogstad 2005; Klvaňová et al. 2011). The difference between male and female nest defence in birds can be explained by several possible explanations, including confidence of parenthood, life-history characteristics, level of testosterone, perception of risk, renesting potential and parental investments (Montgomerie and Weatherhead 1988; Cawthorn et al. 1998).

We have poor knowledge concerning the true nature of the relationship between barred warbler and red-backed shrike. However, the experimental results presented here, together with previous observations (Neuschulz 1988; Tryjanowski and Goławski 2004; Goławski 2007), show that both passerines, especially warblers, quickly detected and intensively responded to predators. They are able to jointly protect their territory against intruders. In both species, the birds engaged in the defence of broods belonging to both conspecifics and the associate species. In this way they should obtain the reciprocal benefit of nesting in close proximity (Clark and Robertson 1979; Richardson and Bolen 1999; Haemig 2001).

Acknowledgments All experimental procedures were approved by the Local Ethic Committee in Lublin. The study was supported by Maria Curie Sklodowska University in Lublin (grant of Vice-Rector for Research and International Cooperation nr. BW-01-1200-01-10). I warmly thank two anonymous referees for their helpful comments on the manuscript, and Wojciech Czarniawski from Department of Zoology UMCS for lending the stuffed models.

Open Access This article is distributed under the terms of the Creative Commons Attribution License which permits any use, distribution, and reproduction in any medium, provided the original author(s) and the source are credited.

\section{References}

Blanco G, Tella JL (1997) Protective association and breeding advantages of choughs nesting in lesser kestrel colonies. Anim Behav 54:335-342

Blomqvist S, Elander M (1988) King Eider (Somateria spectabilis) nesting in association with long-tailed Skua (Stercorarius longicaudus). Arctic 41:138-142

Bogliani G, Sergio F, Tavecchia G (1999) Woodpigeons nesting in association with hobby falcons: advantages and choice rules. Anim Behav 57:125-131
Cawthorn JM, Morris DL, Ketterson ED, Nolan V (1998) Influence of experimentally elevated testosterone on nest defence in darkeyed juncos. Anim Behav 56:617-621

Clark KL, Robertson RJ (1979) Spatial and temporal multi-species nesting aggregations in birds as anti-parasite and ant-predator defences. Behav Ecol Sociobiol 5:359-371

Conway CJ, Martin TE (2000) Evolution of passerine incubation behavior: influence of food, temperature, and nest predation. Evolution 54:670-685

Cramp S (1992) Handbook of the birds of Europe, the Middle east and North Africa. In: The birds of the western Palearctic, vol VI: Warblers. Oxford University Press, Oxford

Cramp S (1993) Handbook of the birds of Europe, the Middle east and North Africa. In: The birds of the western Palearctic, vol VII: flycatchers to shrikes. Oxford University Press, Oxford

Dyrcz A, Grabiński W, Stawarczyk T, Witkowski J (1991) Birds of Silesia. Wrocław University

Ebbinge BS, Spaans B (2002) How do Brent Geese (Branta $b$. bernicla) cope with evil? Complex relationships between predators and prey. J Ornithol 143:33-42

Forsman JT, Hjernquist MB, Taipale J, Gustafsson L (2008) Competitor density cues for habitat quality facilitating habitat selection and investment decisions. Behav Ecol 19:539-545

Ghalambor CK, Martin TE (2000) Parental investment strategies in two species of nuthatch vary with stage-specific predation risk and reproductive effort. Anim Behav 60:263-267

Grim T (2008) Are Blackcaps (Sylvia atricapilla) defending their nests also calling for help from their neighbours? J Ornithol 149:169-180

Goławski A (2007) Does the Red-backed Shrike (Lanius collurio L.) benefits from nesting in the association with the Barred Warbler (Sylvia nisoria Bechst.)? Pol J Ecol 55:601-604

Gotzman J (1965) Die Transspezifischen Räumlichen Beziehungen zwischen dem Neuntöter (Lanius collurio L.) und der Spergrasmücke (Sylvia nisoria Bechst.) in der Brutzeit. Ekologia Polska A 13:1-22

Haemig PD (2001) Symbiotic nesting of birds with formidable animals: a review with applications to biodiversity conservation. Biodiv Conserv 10:527-540

Halme P, Häkkilä M, Koskela E (2004) Do breeding Ural owls Strix uralensis protect ground nests of birds?: an experiment using dummy nests. Wildl Biol 10:145-148

Halupka K, Halupka L (1997) The influence of reproductive season stage on nest defence by meadow pipit (Anthus pratensis). Ethol Ecol Evol 9:89-98

Hogstad O (2004) Nest defence strategies in the Fieldfare Turdus pilaris: the responses on an avian and a mammalian predator. Ardea 92:79-84

Hogstad O (2005) Sex-differences in nest defence in Fieldfares Turdus pilaris in relation to their size and physical condition. Ibis 147:375-380

Hollander FA, Van Overveld T, Tokka I, Matthysen E (2008) Personality and nest defense in the great tit (Parus major). Ethology 114:405-412

Kleindorfer S, Fessl B, Hoi H (2005) Avian nest defence behaviour: assessment in relation to predator distance and type, and nest height. Anim Behav 69:307-313

Klvaňová A, Hořáková D, Exnerová A (2011) Nest defence intensity in House Sparrows Passer domesticus in relation to parental quality and brood value. Acta Ornithol 46:47-54

Krama T, Bērzijš A, Rytkönen S, Rantala MJ, Wheatcroft D, Krams I (2012) Linking anti-predator behaviour and habitat quality: group effect in nest defence of a passerine bird. Acta Ethol 15:127-134

Kryštofková M, Haas M, Exnerová A (2011) Nest defence in Blackbirds Turdus merula: effect of predator distance and parental sex. Acta Ornithol 46:55-63 
Kuźniak S, Bednorz J, Tryjanowski P (2001) Spatial and temporal relations between the Barred Warbler Sylvia nisoria and the Red-backed Shrike Lanius collurio in the Wielkopolska region (W Poland). Acta Ornithol 36:129-133

Kuźniak S, Tryjanowski P (2003) Red-backed Shrike. Świebodzin

Lima SL (2009) Predators and the breeding bird: behavioral and reproductive flexibility under the risk of predation. Bioll Rev 84:485-513

Martin PR, Martin TE (2001) Behavioral interactions between coexisting species: song playback experiments with wood warblers. Ecology 82:207-218

Montgomerie RD, Weatherhead PJ (1988) Risks and rewards of nest defense by parent birds. Q Rev Biol 63:167-187

Mönkkönen M, Husby M, Tornberg R, Helle P, Thomson RL (2007) Predation as a landscape effect: the trading off by prey species between predation risks and protection benefits. J Anim Ecol 76:619-629

Nankinov D, Darakchiev A (1979) Relationships and areal pulsation of the Barred Warbler (Sylvia nisoria Bechst.) and the Red-backed Shrike (Lanius collurio L.). Nautschni Trudovye 17:139-148

Neuschulz F (1981) Brutbiologie einer population der Sperbergrasmücke (Sylvia nisoria) in Norddeutschland. J Ornithol 122:231-257

Neuschulz F (1988) Zur Synőkie von Sperbergrasmücke Sylvia nisoria (Bechst., 1975) und Neuntöter Lanius collurio (L., 1758). Luchow-Dannenberger Orn. Jber. 234

Nocera JJ, Forbes GJ, Giraldeau LA (2009) Aggregations from using inadvertent social information: a form of ideal habitat selection. Ecography 32:143-152

Norrdahl K, Suhonen J, Hemminki O, Korpimäki E (1995) Predator presence may benefit: kestrels protect curlew nests against nest predators. Oecologia 101:105-109

Pavel V, Bureš S (2001) Offspring age and nest defence: test of feedback hypothesis in the meadow pipit. Anim Behav 61:297-303

Polak M (2012) Habitat preferences of the sympatric barred warbler (Sylvia nisoria) and the red-backed shrike (Lanius collurio) breeding in central Poland. Ann Zool Fenn 49 (in press)

Post W, Seals CA (1993) Nesting associations pf Least Bitterns and Boat-tailed Grackles. Condor 95:139-144

Požgayová M, Procházka P, Honza M (2009) Sex-specific defence behaviour against brood parasitism in a host with female-only incubation. Behav Process 81:34-38
Regelmann K, Curio E (1983) Determinants of brood defence in the great tit Parus major L. Behav Ecol Sociobiol 13:131-145

Regelmann K, Curio E (1986) Why do great tit (Parus major) males defend their brood more than females do? Anim Behav 34:12061214

Richardson DS, Bolen GM (1999) A nesting association between semi-colonial Bullock"s orioles and yellow-billed magpies: evidence for the predator protection hypothesis. Behav Ecol Sociobiol 46:373-380

Quinn JL, Prop J, Kokorev Y, Black JM (2003) Predator protection or similar habitat selection in red-breasted goose nesting associations: extremes along a continuum. Anim Behav 65:297-307

Quinn JL, Ueta M (2008) Protective nesting associations in birds. Ibis 150:146-167

Sergio F, Rizzolli F, Marchesi L, Pedrinni P (2004) The importance of interspecific interactions for breeding-site selection: peregrine falcons seek proximity to ravens. Ecography 27:818-826

Stenhouse IJ, Gilchrist HG, Montevecchi WA (2005) An experimental study examining the anti-predator behaviour of Sabine's gulls (Xema sabini) during breeding. J Ethol 23:103-108

Statsoft Statsoft Inc. (2001) Statistica for Windows (data analysis system). Version 6

Tomiałojć L, Stawarczyk T (2003) Avifauna of Poland. Distribution, numbers and changes. "pro Natura". Wrocław

Tøttrup AP, Klaassen RHG, Strindberg R, Thorup K, Kristensen WM, Jørgensen PS, Fox J, Afanasyev V, Rabek C, Alerstam T (2012) The annual cycle of a trans-eqatorial Euroasian-African passerine migrant: different spatio-temporal strategies for autumn and spring migration. Proc R Soc B 279:1008-1016

Tryjanowski P, Goławski A (2004) Sex differences in nest defence by the red-backed shrike Lanius collurio: effects of offspring age, brood size, and stage of breeding season. J Ethol 22:13-16

Tryjanowski P, Goławski A, Kuźniak S, Mokwa T, Antczak M (2007) Disperse or stay? Exceptionally high breeding-site infidelity in the Red-backed Shrike Lanius collurio. Ardea 95:316-320

van Kleef HH, Willems F, Volkov AE, Smeets JHR, Nowak D, Nowak A (2007) Dark-bellied brent geese Branta b. bernicla breeding near snowy owl Nyctea scandiaca nests lay more and larger eggs. J Avian Biol 38:1-6

Welbergen JA, Davies NB (2011) A parasite in wolf's clothing: hawk mimicry reduces mobbing of cuckoos by hosts. Behav Ecol 22:574-579 